\title{
EN TORNO A LA JUSTICIA CONSTITUCIONAL EN LATINOAMÉRICA Y ALGUNOS DESAFÍOS TEMÁTICOS POR AFRONTAR
}

\author{
VÍCTOR BAZÁN
}




\section{SUMARIO}

I. PLAN DEL TRABAJO. II. APRECIACIONES CONTEXTUALES. III. ALGUNAS LÍNEAS TEMÁTICAS POR ABORDAR O PROFUNDIZAR: 1. La exploración y la utilización equilibradas y razonadas de sentencias "atípicas» $\mathrm{o}$ «intermedias». 2. La jurisdicción constitucional frente a la inconstitucionalidad por omisión. 3. Acerca del control de constitucionalidad de los instrumentos internacionales. 4. En torno a la participación de amicus curiae en los procesos constitucionales. 5. Sobre la efectivización de los derechos económicos, sociales y culturales. 6. La interacción de la jurisdicción constitucional interna con los tribunales internacionales para fortalecer la preservación de los derechos fundamentales. IV. EPÍLOGO. 


\title{
EN TORNO A LA JUSTICIA CONSTITUCIONAL EN LATINOAMÉRICA Y ALGUNOS DESAFÍOS TEMÁTICOS POR AFRONTAR $\left(^{*}\right)$
}

\author{
POR \\ VÍCTOR BAZÁN ${ }^{* *}$
}

\section{PLAN DEL TRABAJO}

En el presente trabajo enfocaremos principalmente algunos retos temáticos que sobre la justicia constitucional latinoamericana se posan, y que desafían las posibilidades de fortalecimiento de sus (anhelables) roles de defensora de la Constitución, último reducto tuitivo de los derechos humanos en el plano interno y pieza importante de sostén de la institucionalidad democrática en su función de armonizadora de los poderes del Estado.

$\left(^{*}\right)$ Con profunda honra nos sumamos a la feliz idea del Consejo de Redacción de la Revista de Derecho Politico en punto a rendir un largamente merecido homenaje al profesor Manuel GARCíAPELAYO con ocasión de la celebración de su centenario, en mayo de 2009. Felicitamos a los impulsores de la idea y, en particular, agradecemos la invitación que nos extendieran al efecto los apreciados amigos y colegas profesores Antonio TORRES DEL MORAL y Javier TAJADURA TEJADA.

(**) Profesor Titular Efectivo de Derecho Constitucional de la Facultad de Derecho y Ciencias Sociales de la Universidad Católica de Cuyo (San Juan, Argentina). Fundador y actual Director del Instituto de Derecho Constitucional, Procesal Constitucional y Derechos Humanos de la misma Facultad. Miembro del Comité Ejecutivo de la Asociación Argentina de Derecho Constitucional. Miembro de los Institutos Iberoamericanos de Derecho Procesal Constitucional y de Derecho Constitucional. 
Justamente en torno a esta última cuestión, explica PEGORARO que «el crecimiento de las 'demandas' de justicia constitucional, la ampliación de los parámetros y del objeto del juicio, las estrechas y frecuentes relaciones establecidas con el poder legislativo, el incremento del 'rol público' de los Tribunales, han contribuido al incremento de las motivaciones de las sentencias constitucionales. En ellas los Tribunales no se limitan a describir los nexos del discurso lógico, con meras referencias 'per relationem' a las disposiciones afectadas. Al contrario, se valen de todos los instrumentos de la retórica, hacen amplias referencias a los precedentes, acuden al derecho comparado y a la jurisprudencia de otros Tribunales, operan 'excursus' históricos de institutos y disciplinas, expresan valoraciones y ponderaciones de valores, critican, sugieren, aconsejan, armonizan los poderes del Estado» ${ }^{1}$ —énfasis añadido-.

Retomando la línea de anunciación del itinerario propuesto, y sin ánimo de taxatividad, ingresaremos a la problemática de la utilización de sentencias «atípicas» o «intermedias», que debe ser equilibrada y razonada; nos detendremos en las posibilidades de sustentación del control respecto de las omisiones inconstitucionales; argumentaremos sobre la conveniencia de instrumentar el control de constitucionalidad previo y obligatorio de los instrumentos internacionales o mantenerlo incólume en caso de que ya estuviera así implementado en el texto de la Ley Fundamental; subrayaremos la utilidad de abrir nuevas fórmulas de participación de la ciudadanía en los procesos constitucionales, por ejemplo, a través de la intervención de amicus curiae; resaltaremos la necesidad de fortalecer los mecanismos internos de exigibilidad y justiciabilidad de los derechos económicos, sociales y culturales (DESC); e insistiremos en la indispensable búsqueda de una pacífica y eficaz interacción de la jurisdicción constitucional interna con los tribunales internacionales para fortalecer la salvaguardia de los derechos fundamentales.

Como puede suponerse, tales cuestiones no son sino sólo algunos de los puntos temáticos que el Siglo XXI impone a la jurisdicción constitucional en diversas latitudes de este sector geográfico del continente americano.

\section{APRECIACIONES CONTEXTUALES}

A modo de premisas conceptuales que iluminarán jurídica y axiológicamente el presente trabajo, es preciso reiterar — con BIDART CAMPOS— que la

1 Pegoraro, Lucio, «Clasificaciones y modelos de justicia constitucional en la dinámica de los ordenamientos», Revista Iberoamericana de Derecho Procesal Constitucional, No 2, julio-diciembre de 2004, Instituto Iberoamericano de Derecho Procesal Constitucional, Porrúa, México, D.F., pp. $143 / 144$. 
Constitución se ha juridizado, es «derecho de la Constitución», es decir que se ha superado la idea de Constitución preponderantemente como un plan o proyecto político sin fuerza o vigor normativos ${ }^{2}$. Por el contrario, al cambiar el enfoque y adjudicar a aquélla tal fuerza o vigor, se ha reforzado la tradicional doctrina de la supremacía constitucional, porque se le asigna aplicación directa como norma jurídica de base (o de vértice) ${ }^{3}$. Ello significa que el contenido de la Constitución se ha sustancializado mediante el denso bloque axiológico que aglutina valores, principios y derechos, en un sistema axiológico que tiene como centro a la persona humana, por lo que la Constitución ya no admite ser visualizada desde el poder, sino desde la persona, de modo que su eje no es la organización del poder sino el núcleo material de valores, principios y derechos que asignan a la misma Constitución una unidad de orden y de sentido ${ }^{4}$.

Convergentemente, Rolla apunta que la Constitución no alberga únicamente un conjunto de normas, sino que además contiene la afirmación de principios y valores que unifican una comunidad social, por lo que el deber actual del juez constitucional consiste en ser dinámico artífice de la integración social dentro del Estado y un garante de la unidad sustancial del ordenamiento 5 .

En esa línea analítica, creemos que el autor italiano citado en último término acierta cuando afirma que entre Constitución democrática y derechos fundamentales se establece una relación dialéctica pues por una parte la Constitución (en tanto fuente suprema del ordenamiento - junto a los instrumentos internacionales sobre derechos humanos con jerarquía equivalente a ella, nos permitimos añadir por nuestra parte-) constituye la base de su reconocimiento y tutela; $y$, por otra parte, el goce del contenido esencial de los derechos fundamentales es la condición elemental para la subsistencia del Estado Democrático de Derecho ${ }^{6}$.

2 Bidart CAMPOS, Germán J., «La positivización de la axiología constitucional (Para una teoría de la Constitución en el Estado Social y Democrático de Derecho)», en Raúl Morodo y Pedro De VegA (dirs.), Estudios de Teoría del Estado y Derecho Constitucional en honor de Pablo LUCAS VERDÚ, T ${ }^{\circ}$ II, Universidad Nacional Autónoma de México (UNAM) y Servicio de Publicaciones de la Facultad de Derecho de la Universidad Complutense de Madrid, Madrid, 2000, p. 729.

3 Ídem.

${ }^{4}$ Ídem.

5 Rolla, Giancarlo, «El papel de la justicia constitucional en el marco del constitucionalismo contemporáneo", en VEGA GÓMEZ, Juan y CORZO SOSA, Edgar (coords.), 'Instrumentos de tutela y justicia constitucional', Memoria del VII Congreso Iberoamericano de Derecho Constitucional (México, D.F., 12 a 15 de febrero de 2002), Instituto de Investigaciones Jurídicas (IIJ), UNAM, México, D.F., 2002, p. 364.

${ }^{6}$ Rolla, Giancarlo, Justicia constitucional y derechos fundamentales, Biblioteca Peruana de Derecho Constitucional, $\mathrm{N}^{\circ} 28$, Instituto Iberoamericano de Derecho Constitucional (Sección Peruana), Grijley, Lima, 2008, p. 56. 
Y, en esa vinculación de Constitución y derechos fundamentales, la justicia constitucional es parte esencial, moldeándose -como grafica RolLA- una especie de triángulo equilátero, que enlaza una trilogía de características básicas del constitucionalismo contemporáneo: principio de legalidad, garantía de los derechos fundamentales y justicia constitucional ${ }^{7}$.

\section{ALGUNAS LÍNEAS TEMÁTICAS POR ABORDAR O PROFUNDIZAR}

Sin pretensiones de taxatividad, nos limitaremos a elaborar sucintas reflexiones acerca de institutos, instrumentos o herramientas que pueden resultar provechosos para el desarrollo de la eminente labor a cargo de la justicia constitucional en los ámbitos de defensa y realización de la Constitución, de protección de los derechos humanos y de cumplimiento de su papel de moderadora institucional.

Como aclaración al margen, es preciso puntualizar que en algún caso el cambio de perspectiva y de rumbo jurisprudenciales propuestos deberán acompanarse de una consistente modificación normativa que habilite expresamente la competencia que legitime una innovación en tal sentido.

\section{La exploración y la utilización equilibradas y razonadas de sentencias «atipicas» 0 «intermedias»}

A. Superación del esquema kelseniano binario puro

Altri tempi muy provechoso, el simplificado esquema que KELSEN inicialmente manejara, reducido a distinguir dos únicos tipos de sentencias (estimatorias y desestimatorias) y a considerar al Tribunal Constitucional como un mero legislador negativo cuyas resoluciones no podían conllevar más creación de Derecho que la escueta anulación de la ley, desde hace tiempo se vio desbordado por la realidad funcional de los órganos de cierre de la jurisdicción constitucional y los requerimientos del Estado Constitucional de Derecho ${ }^{8}$.

7 Ibid., p. 57.

8 Cftar. Garrorena Morales, Ángel, «Opacidad y desestimación de la inconstitucionalidad en el fallo de las sentencias interpretativas", en AA.VV., La Democracia Constitucional. Estudios en homenaje al Profesor Francisco RUBIO LLORENTE, Vol. 2, Congreso de los Diputados, Tribunal Cons- 
Se constata, así, que la alternativa constitucionalidad-inconstitucionalidad resulta insuficiente para cubrir todo el espectro cualitativo de casos que ante aquéllos se presentan, lo que ha requerido la generación de posiciones jurisdiccionales activistas para modelar variantes sentenciales que permitan a los tribunales desempeñar de modo más adecuado el relevante rol que están llamados a cumplir?.

En esa lógica, principalmente en Europa (por ejemplo, en los Tribunales Constitucionales de Alemania, Austria, España y la Corte Constitucional de Italia), aunque con irradiaciones hacia la región latinoamericana (v.gr., en la Corte Constitucional de Colombia, los Tribunales Constitucionales de Perú y Bolivia, la Corte Suprema de Justicia argentina — que pareciera busca acercarse a un tribunal constitucional desde el plano funcional ${ }^{10}-$ y las Salas Constitucionales de la Corte Suprema de Justicia de Costa Rica y del Tribunal Supremo de Justicia de Venezuela), fue plasmándose la construcción jurisprudencial de «sentencias atípicas o intermedias» que, como se sabe, reconocen una génesis primordialmente práctica como válvula de escape al rígido molde que inicialmente proyectara KELSEN encapsulando a los tribunales constitucionales en el exclusivo rol de «legisladores negativos».

Aunque justo es reconocer que en no todas las latitudes de Latinoamérica han permeado estas modalidades sentenciales, observándose en algunas de aquéllas sólo muestras esporádicas que lejos están de dar cuerpo a una doctrina sistemática y uniforme del respectivo órgano de cierre de la justicia constitucional.

\section{B. Acercamiento taxonómico}

En torno a las variantes decisionales en cuestión existen casi tantas clasificaciones como autores se embarcan en intentos taxonómicos a su respecto, lo

titucional, Universidad Complutense de Madrid, Fundación Ortega y Gasset, Centro de Estudios Políticos y Constitucionales (CEPC), Madrid, 2002, pp. 1844/1845.

9 Sobre el punto, ver BAZÁN, Víctor, por ejemplo en «De jueces subrogantes, casos difíciles y sentencias atípicas», Jurisprudencia Argentina, Abeledo-Perrot, 15 de agosto de 2007, Buenos Aires, pp. 23/33.

${ }_{10} \mathrm{Al}$ respecto, vid. BAZÁN, Víctor, ejemplificativamente, en «Derecho Procesal Constitucional: estado de avance, retos y prospectiva de la disciplina», Revista Iberoamericana de Derecho Procesal Constitucional, $N^{\circ}$ 8, julio-diciembre de 2007, Instituto Iberoamericano de Derecho Procesal Constitucional, Porrúa, México, D.F., pp. 89/112; y con mayor detalle, «La reconfiguración del rol institucional de la Corte Suprema de Justicia argentina y el camino hacia su consolidación como un tribunal constitucional», Anuario de Derecho Constitucional Latinoamericano 2008, Fundación Konrad Adenauer, Montevideo, 2008, pp. 25/61. 
que demuestra la dificultad de lograr acuerdos absolutos en punto a su sistematización.

Cuando menos, existe algún consenso en dar por sentado que la citada problemática de la interpretación conforme a la Constitución (Verfassungskonforme Auslegung en la terminología alemana) mucho tiene que ver con el nacimiento y la multiplicación de estos instrumentos sentenciales. Según GropPI, la idea se inscribe en el marco de la "'minimización' del impacto de las decisiones de inconstitucionalidad sobre el sistema, a fin de evitar vacíos y de buscar un equilibrio entre la necesidad de eliminar normas inconstitucionales y la de no crear lagunas o discontinuidades que pondrían en duda el carácter de ordenamiento jurídico (...). Con las sentencias interpretativas el juez constitucional hace propia una de las interpretaciones posibles de la disposición censurada, escogiendo la que es conforme (sentencia interpretativa de rechazo) o la contraria (sentencia interpretativa estimatoria) a la Constitución» ${ }^{11}$.

Estando las «sentencias interpretativas" vinculadas a la interpretación conforme, ellas parten del presupuesto de la distinción entre disposición y norma, o entre el enunciado normativo y la norma que, por medio de la interpretación constitucional, se desprende del mismo. Ligada a tal faceta de la cuestión, una de las numerosas aproximaciones que se han ensayado sobre las sentencias interpretativas -en este caso la surgente de la pluma de RUBIO LLORENTE- las entiende como aquellas que emiten un pronunciamiento, no sobre el enunciado de la ley sino de una norma que de él puede deducirse mediante los medios habituales de interpretación ${ }^{12}$.

Ilustrativamente, y dentro de la categorización de las «interpretativas», hay quienes ubican por ejemplo a las sentencias "manipulativas», que a su vez, pueden ser «sustitutivas», «reductoras» o «aditivas». Es, por citar un caso referencial, la posición de GASCÓN, para quien las primeras sustituyen una interpretación plausible, pero inconstitucional, del precepto legal impugnado, por otra que claramente no se deduce del mismo, pero que resulta acorde con la Constitución; las «reductoras» suponen precisamente una interpretación restrictiva del ámbito de aplicación del precepto legal impugnado para conformarlo a la Constitución, como producto de lo cual, y luego de la tarea interpretativa, la regla

${ }^{11}$ GroppI, Tania, «¿Hacia una justicia constitucional 'dúctil'? Tendencias recientes de las relaciones entre Corte Constitucional y jueces comunes en la experiencia italiana», en FERRER MAC-Gregor, Eduardo (coord.), Derecho Procesal Constitucional, T ${ }^{\circ}$ I, 4a ed., Colegio de Secretarios de la Suprema Corte de Justicia de la Nación, Porrúa, México, D.F., 2003, p. 355.

12 Rubio Llorente, Francisco, «La jurisdicción constitucional como forma de creación del derecho, en La forma del poder. Estudios sobre la Constitución, 2a ed., Centro de Estudios Constitucionales, Madrid, 1997, p. 484. 
deja de ser aplicable en uno o varios de los supuestos comprendidos en abstracto por el enunciado legal; y las "aditivas", asociadas a la inconstitucionalidad por omisión relativa (problemática que de modo general abordaremos enseguida), consisten en una interpretación extensiva del radio de acción del precepto legal objetado, para conformarlo a la Constitución, de resultas de lo cual y tras la interpretación, la regla es aplicable a más supuestos de los comprendidos en abstracto por el enunciado legal'3.

En el necesariamente restringido contexto de este muestreo enunciativo, no podríamos dejar de referir a un enfoque taxonómico que las divide en unilaterales y bilaterales ${ }^{14}$.

Las primeras remedian inmediatamente la inconstitucionalidad modificando la norma considerada inconstitucional, o sea, el tribunal constitucional actuaría como legislador positivo, v.gr., las citadas sentencias interpretativas y las que contienen una declaración de inconstitucionalidad parcial, ya cuantitativa, ya cualitativa.

De su lado, las nombradas en segundo término suponen una interacción entre el tribunal o corte constitucionales con el poder legislativo y/o con la magistratura ordinaria (incluso podrían denominarse multilaterales si involucran a otro u otros órganos públicos además del Congreso o Parlamento). Entre aquéllas se puede incluir, inter alia, a las declaraciones de mera incompatibilidad o de inconstitucionalidad sin nulidad o de inconstitucionalidad simple; las sentencias apelatorias; las sentencias exhortativas y las «sentencias aditivas de principio»o las «sentencias-delegación» ${ }^{15}$.

Faceta funcional importante de la cuestión que tratamos es el de la modulación de los efectos de los pronunciamientos por los órganos de justicia constitucional ${ }^{16}$. En tal sentido, pueden contabilizarse enunciativamente, las sen-

${ }^{13}$ Cfr. GasCón, Marina, voz «Interpretación conforme (con la Constitución)», en CARBONELL, Miguel (coord.), Diccionario de derecho constitucional, Porrúa y UNAM, México, D.F., 2002, p. 318.

${ }^{14}$ AjA, Eliseo y GonZÁLEZ BeILfuss, Markus, «Conclusiones generales», AJA, Eliseo (ed.), Las tensiones entre el Tribunal Constitucional y el legislador en la Europa actual, Ariel, Barcelona, 1998, pp. 274 y ss.

15 Ver Díaz Revorio, Francisco, «El control de constitucionalidad de las omisiones legislativas relativas en el derecho comparado europeo", Revista Española de Derecho Constitucional, № 61, Año 21, enero-abril 2001, CEPC, Madrid, pp. 85/86.

16 Mutatis mutandi, y en referencia al contexto español, se ha afirmado que, más allá de purismos dogmáticos, la posibilidad de modular los efectos de la nulidad, lejos de debilitar la eficacia del control de constitucionalidad, en la práctica lo refuerza, ya que permite que el Tribunal actúe con mayor libertad al poder cohonestar la declaración de inconstitucionalidad, cuando ésta es necesaria, con la ponderación, no menos necesaria y siempre presente, de las consecuencias prác- 
tencias que retrasan sus efectos para dar tiempo a la intervención del legislador o las que declaran que la ley «todavía no es inconstitucional». En este punto, es interesante traer a colación las denominadas «sentencias prospectivas», cuyo origen puede ubicarse en la Suprema Corte de Justicia de EE.UU., y que, naturalmente, no tienen eficacia retroactiva, sino que producen efectos pro futuro quedando fijado en las mismas el plazo en que ello ocurrirá. Al respecto, GARCíA DE ENTERRÍA individualiza como punto de partida de tal modalidad sentencial en la jurisprudencia norteamericana a la pronunciada en «Linkletter v. Walker», de $1965^{17}$, "que rompe conscientemente con el "principle of absolute retroactivity invalidity', por el argumento pragmático de que tal principio aplicado en el caso (una precisión sobre las garantías del proceso penal, especialmente sobre la prueba capaz de justificar un veredicto de culpabilidad) implicaría una grave perturbación de la Administración de la justicia; con ello se pretende 'the purpose to be served by the new standards' ${ }^{18}$ (el propósito de servirse de los nuevos estándares).

\section{Advertencia final}

Obviamente, y como en otros ámbitos en cuya superficie la justicia constitucional despliega su labor, en punto a tal abanico de variantes sentenciales deberá aquélla conducirse con prudencia y mostrarse consciente de sus límites, previsora de las consecuencias de sus pronunciamientos y respetuosa del reparto de competencias y funciones que a los distintos poderes del Estado se les asigna para operar en la respectiva dinámica institucional.

En definitiva, la importante y polifacética cuestión que tratamos nos tiende el puente hacia el tema que abordaremos a continuación: las posibilidades de sustentación del control sobre las omisiones inconstitucionales en el Estado Constitucional y Democrático de Derecho.

\footnotetext{
ticas que sobre otros bienes constitucionalmente protegidos puede producir una declaración de nulidad sin modulaciones temporales (VIVER PI-SUNYER, Carles, en ESPÍN TEMPLADO, Eduardo et al., La reforma de la justicia constitucional, Ministerio de Justicia, Centro de Estudios Jurídicos, Thomson - Aranzadi, Navarra, 2006, p. 94).

17381 U.S. 618 (1965)

18 GarCía De ENTERRÍA, Eduardo, La Constitución como norma y el Tribunal Constitucional, Civitas, reimpr., Madrid, 1991, p. 181, nota 124.
} 


\section{La jurisdicción constitucional frente a la inconstitucionalidad por omisión ${ }^{19}$}

A. Liminar

Como se indicara varias décadas atrás en referencia a las normas que el legislador ordinario debía dictar para dar plena ejecución a la Constitución, cuando éste se abstiene de estatuir, por ese camino viene a violar gravemente la Constitución $^{20}$.

Dicho de otra manera, la Constitución puede ser vulnerada no sólo por acción, sino, también, por omisión; concretamente en este último caso, cuando no se actúa a pesar de la expresa previsión constitucional dirigida a que se lo haga o cuando se regula de modo deficiente plasmando una reglamentación insuficiente o discriminatoria que deja de dotar a algunos de lo que, en igualdad de condiciones o circunstancias, acuerda a otros (tema sobre el que volveremos). Ello sentado, ¿sería legítimo permitir que los órganos del poder constituido, mediante su inercia, inhiban la vigencia de la Constitución o paralicen el ejercicio de algún derecho contenido en un mandato constitucional y sujeto a desarrollo normativo ulterior? La respuesta al interrogante debería ser negativa ya que la supremacía de la Constitución es indisponible para aquellos órganos.

La activación del contralor sobre la inercia inconstitucional persigue entre otros objetivos recomponer el imperio de la Ley Fundamental, cuya supremacía habría quedado momentáneamente bloqueada por la agresión negativa del órgano omitente. En línea con ello, cabe recordar que el control de constitucionalidad como noción jurídica es inseparable de la de Constitución como norma suprema de un ordenamiento jurídico dado ${ }^{21}$.

Aunque obvio viene bien recordar que el Estado contemporáneo es Estado Constitucional, en cuyo marco la Carta Fundamental ocupa un lugar central en

19 Sobre la problemática de la inconstitucionalidad por omisión en general, pueden consultarse -entre otros- los siguientes trabajos de BAZÁN, Víctor: «Un sendero que merece ser transitado: el control de la inconstitucionalidad omisiva», en el libro colectivo coordinado por el mismo autor, Desafios del control de constitucionalidad, Ediciones Ciudad Argentina, Buenos Aires, 1996, pp. 171/269; y «Hacia la plena exigibilidad de los preceptos constitucionales: el control de las omisiones inconstitucionales. Especial referencia a los casos de Brasil y Argentina», en la obra colectiva bajo la coordinación de dicho autor, Inconstitucionalidad por omisión, Temis, Bogotá, 1997, pp. $41 / 108$.

20 Biscaretti Di Ruffia, Paolo, Derecho Constitucional, Colección de Ciencias Sociales, N 48, Tecnos, trad. de Pablo Lucas Verdú, Madrid, 1965, p. 269.

${ }^{21}$ VILLAVERde MENÉndeZ, Ignacio, La inconstitucionalidad por omisión, $\mathrm{M}^{\mathrm{c}} \mathrm{Graw}-\mathrm{Hill}$, Madrid, 1997, p. 3. 
el sistema jurídico ${ }^{22}$ (junto a los instrumentos internacionales universales y regionales básicos en materia de derechos humanos con valencia homóloga a ella en aquellos sistemas jurídicos que así lo hayan determinado ${ }^{23}$ ) y ostenta fuerza normativa, lo que supone la imperiosa obligación de garantizar la indemnidad de la Constitución, sea que los ataques en su contra se produzcan por acción o por omisión.

Con todo, y para comprender las raíces y los perfiles de la presente indagación, no son insignificantes las palabras de ZAGREBELSKY, para quien si bien existen en su origen «relevantes distancias entre los sistemas de garantía jurisdiccional de la Constitución: Judicial Review o justicia constitucional; tradiciones de Common o Civil Law; control abstracto o concreto, preventivo o subsecuente; tutela de los derechos constitucionales o control de las leyes, etcétera, el Estado de

${ }^{22}$ Ver sobre el punto, BAZÁN, Víctor, «Neoconstitucionalismo e inconstitucionalidad por omisión", Revista Derecho del Estado, № 20, Universidad del Externado, diciembre de 2007, Bogotá, Colombia, pp. 121/144.

${ }^{23}$ Por citar un caso ejemplificativo, el art. 75 , inc. 22, párr. $2^{\circ}$, de la Constitución argentina — de acuerdo con la reforma de 1994- elabora la siguiente nómina de instrumentos internacionales sobre derechos humanos a los que ha acordado jerarquía constitucional: la Declaración Americana de los Derechos y Deberes del Hombre; la Declaración Universal de Derechos Humanos; la Convención Americana sobre Derechos Humanos; el Pacto Internacional de Derechos Económicos, Sociales y Culturales; el Pacto Internacional de Derechos Civiles y Políticos y su Protocolo Facultativo; la Convención sobre la Prevención y la Sanción del Delito de Genocidio; la Convención Internacional sobre la Eliminación de todas las Formas de Discriminación Racial; la Convención sobre la Eliminación de todas las Formas de Discriminación contra la Mujer; la Convención contra la Tortura y otros Tratos o Penas Crueles, Inhumanos o Degradantes; y la Convención sobre los Derechos del Niño.

A tal registro originario (que en total suma once documentos) se han añadido ex post, con alcurnia homóloga a la Ley Fundamental, la Convención Interamericana sobre Desaparición Forzada de Personas (a la que se ha deparado tal calidad por medio de la Ley $\mathrm{N}^{\circ} 24.820$, publicada el 29 de mayo de 1997) y la Convención sobre la Imprescriptibilidad de los Crímenes de Guerra y de los Crímenes de Lesa Humanidad (instrumento al que se le ha conferido esa valía mediante la Ley $\mathrm{N}^{\circ} 25.778$, publicada el 3 de setiembre de 2003).

Sobre la cuestión en Argentina, véase de BAZÁN, Víctor, «La Corte Suprema de Justicia argentina y su rol en la articulación del derecho internacional de los derechos humanos y el derecho interno", Revista de Derecho Político, N ${ }^{\circ} 73$, Universidad Nacional de Educación a Distancia (UNED), septiembre-diciembre de 2008, Madrid, pp. 315/373.

En torno al tema en el derecho comparado, ver el mismo autor, por ejemplo, en «Conexiones y tensiones entre el derecho internacional de los derechos humanos y el derecho interno en Latinoamérica», en VELÁSQUEZ RAMírez, Ricardo y Bobadilla ReYES, Humberto (coords.), Justicia constitucional, derecho supranacional e integración en el derecho latinoamericano, "VII ${ }^{a}$ Convención Latinoamericana de Derecho", Santiago de Chile, 8 a 12 de octubre de 2007, Grijley, Lima, 2007, pp. 269/307. 
Derecho no siempre es la misma cosa en cuanto État de droit, Rechtsstaat o Rule of law. La noción de Estado Constitucional, por consiguiente, no coincide en todas partes. La misma Constitución no es una norma suprema en la misma medida, en donde cambian las relaciones entre Cortes y poderes legislativos. Son diferencias relevantes. Pero justo por eso se destacan las tendencias comunes que se hallan en el 'juzgar en derecho constitucional'. El Estado Constitucional, que deriva de las diversas nociones de Estado de derecho, parece convertirse en una perspectiva común $»^{24}$ (bastardillas del original).

Por su parte, DE ОтTO explica que la promulgación de una Constitución escrita es prácticamente imprescindible para establecer una norma suprema en el ordenamiento, lo que debe complementarse especificándose que la infracción de lo dispuesto en la misma es antijurídica. En cambio, si el ordenamiento no determina tales pautas, los preceptos de ésta serán constitucionales sólo en cuanto están incluidos en ella, pero en realidad no serán ni siquiera normas, dado que una norma que puede ser infringida lícitamente no es una norma ${ }^{25}$. Al respecto, acota que si el ordenamiento preceptúa que es obligatorio acatar la Constitución escrita, todos sus preceptos son igualmente obligatorios, sea cual fuere la materia de que se ocupen, y a todos les corresponde por igual la condición de norma suprema $^{26}$ (énfasis del original).

\section{B. Variantes tipológicas}

Inmerso en la lógica descripta, y con adscripción al Estado Constitucional de Derecho, se fundamenta y legitima el control de constitucionalidad ejercitable sobre las omisiones que resultan lesivas de la Ley Fundamental, en tanto la vigencia sociológica de ésta es presupuesto de intangibilidad de los mencionados caracteres vertebrales de supremacía y normatividad.

$\mathrm{Al}$ respecto, es siempre conveniente reenviar a WESSEL ${ }^{27}$ cuando de afrontar la tipología de omisiones inconstitucionales se trata. En una simplificación ta-

${ }^{24}$ Cfr. Zagrebelsky, Gustavo, «El juez constitucional en el Siglo XXI», trad. de Eduardo Ferrer Mac-Gregor, texto escrito de la conferencia pronunciada en el « ${ }^{\text {er }}$ Congreso Internacional de Justicia Constitucional y V ${ }^{\circ}$ Encuentro Iberoamericano de Derecho Procesal Constitucional», Suprema Corte de Justicia de México e Instituto Iberoamericano de Derecho Procesal Constitucional, Cancún, 14 al 17 de mayo de 2008.

25 De Oтто, Ignacio, Derecho Constitucional. Sistema de fuentes, 5a reimpr., Ariel, Barcelona, 1997, pp. 17/18.

26 Ibid., p. 18.

27 WESSEL, «Die Rechtsprechung des Bundesverfassungsgerichts zur Verfassungsbeschwerde», Deutsches Verwaltungsblatt (DVBl), cuad. 6, 1952, p. 164. 
xonómica extrema (pues profundizar en otras variantes tipológicas de preterición excedería el objeto del presente señalamiento) nos limitamos a indicar que ellas pueden ser: absolutas o totales, cuando directamente media ausencia de la norma que debería regular una determinada situación jurídica fijada constitucionalmente; y relativas o parciales, cuando el legislador, al emitir la norma para cumplir el mandato constitucional, y en equivalencia de condiciones y circunstancias, favorece a ciertos grupos y, sin fundamento objetivo, deja de lado a otros o concede ventajas a unos que no son dispensadas a otros, es decir que, al legislar, lesiona el principio de igualdad (con su presupuesto de no discriminación) o emite una regulación deficiente gestada por una regla incompleta o normativamente insuficiente.

Avanzando en esa línea argumental, con un punto de toque con la problemática que analizamos, puede incluso plantearse la cuestión vinculada al defecto de pronóstico o de prognosis del legislador, esto es, el que gira en derredor de las reglas que, dictadas para operativizar un mandato constitucional concreto, habrían sufrido desgaste o desfase deviniendo anacrónicas y, consiguientemente, disvaliosas. Ello da lugar al interrogante de si la omisión del legislador en actualizarlas, es idónea para desencadenar la corrección jurisdiccional.

\section{El radio de acción de la magistratura constitucional}

Con todo, es indispensable al menos bosquejar el perímetro y la superficie con que cuenta la magistratura constitucional para analizar el cuadro de situación que le permita descubrir la presencia de pretericiones inconstitucionales y generar los remedios para superarlas. Tal labor requerirá dosis importantes de prudencia y rigor en orden a sortear el riesgo de deslizarse hacia una «trivialización» de las declaraciones de inconstitucionalidad al ritmo de la insensatez o el apresuramiento.

En esta dinámica reflexiva con que debe actuar el magistrado constitucional para descifrar si convergen o no los requisitos configurativos de la inconstitucionalidad por omisión, no debería prescindirse de un balance cuidadoso y realista de las diversas pautas en juego: normatividad y primacía de la Constitución; connotaciones axiológicas del derecho alegado o de la situación jurídica contraria a la Constitución que la omisión provoca; lapso de tiempo por el que viene manteniéndose la pasividad del órgano deferente; margen de acción (o de inacción) del legislador o de la autoridad pública comprometida; abanico de posibilidades al alcance de la judicatura para disponer la efectivización de una solución material y financieramente posible; y, entre otros aspectos, el deber de ejercer cabalmente el control de constitucionalidad. 
Semejante ejercicio jurisdiccional supone naturalmente tener siempre presente la obligación de generar una solución equilibrada que ni signifique una temeraria invasión de sectores de atribuciones propios de otros poderes estatales, ni enerve la actuación judicial si el órgano competente obtura arbitrariamente la vigencia de la supremacía constitucional al omitir sine die el cumplimiento de los mandatos constitucionales $\mathrm{o}$, ya en tarea de desarrollo constitucional, excluye injustificada y discriminatoriamente a algunos de lo que concede a otros en igualdad o equivalencia de circunstancias.

\section{Breve recorrido por el derecho comparado}

Para ilustrar este acercamiento, realizaremos una visita panorámica por el derecho comparado para recordar que el tema de la inconstitucionalidad por omisión ha sido institucionalizado por las siguientes vías ${ }^{28}$ :

- las Constituciones Nacionales, por ejemplo en Portugal y Hungría, en dominios europeos; en Brasil, Ecuador ${ }^{29}$ y Venezuela, ya en Latinoamérica; o en Angola y Timor, en latitudes africana y asiática respectivamente;

- la senda legal directa en Costa Rica, por medio de la Ley $\mathrm{N}^{\circ} 7.135$, de 11 de octubre de 1989; o mediata en cuanto a las omisiones legislativas, en España, donde por conducto de la reforma de la Ley Orgánica del Tribunal Constitucional implementada por la Ley Orgánica Nº 6/2007, de 24 de mayo, el recurso de amparo en defensa de los derechos fundamentales puede tener ahora por objeto también las omisiones de los ór-

${ }^{28}$ Un acercamiento a la inconstitucionalidad por omisión en perspectiva iuscomparada puede verse en BAZÁN, Víctor, «Respuestas normativas y jurisdiccionales frente a las omisiones inconstitucionales: una visión de derecho comparado", en CARBONELL, Miguel (coord.), En busca de las normas ausentes. Ensayos sobre la inconstitucionalidad por omisión, 2a ed., IIJ, UNAM, México, D.F., 2007, pp. 75/270; y «La inconstitucionalidad por omisión en el derecho comparado, con particular referencia al sistema venezolano», Anuario de Derecho Constitucional Latinoamericano 2006, T ${ }^{\circ}$ I, Fundación Konrad Adenauer, Montevideo, 2006, pp. 475/506.

${ }^{29} \mathrm{La}$ actual Constitución del Ecuador, aprobada por el referéndum de 28 de septiembre de 2008, incluye en el cuadro competencial de la Corte Constitucional la atribución de "[d]eclarar la inconstitucionalidad en que incurran las instituciones del Estado o autoridades públicas que por omisión inobserven, en forma total o parcial, los mandatos contenidos en normas constitucionales, dentro del plazo establecido en la Constitución o en el plazo considerado razonable por la Corte Constitucional. Si transcurrido el plazo la omisión persiste, la Corte, de manera provisional, expedirá la norma o ejecutará el acto omitido, de acuerdo con la ley» -énfasis añadido- (art. 436, inc. 10). 
ganos judiciales y de las autoridades administrativas, lo que no excluye la posibilidad de un control mediato del poder legislativo ${ }^{30}$;

- las Constituciones locales en países con estructura federal como Brasil, México y Argentina; y

- el despliegue jurisprudencial de los Tribunales Constitucionales de Alemania y España y la Corte Constitucional italiana, en Europa; y por la Corte Constitucional de Colombia (por ejemplo, Sentencias Nos. C073/96, C-543/96, C-540/97, C-080/99, C-956/99, C-427/00, C1433/00, C-007/01, C-1064/01, C-041/02, C-185/02, C-871/02, C402/03, C-858/06), los Tribunales Constitucionales del Perú (v.gr., Expte. $\mathrm{N}^{\circ}$ 2.945-2003-AA/TC, in re "A.A.M.G.») y de Bolivia (en la Declaración Constitucional No 06/2000 y las Sentencias Constitucionales 0009/2004 y 0018/2004), las Supremas Cortes de Justicia de República Dominicana (sentencia recaída in re "Productos Avon S.A.», de 24 de febrero de 1999), México (las Controversias constitucionales 46/2002 de 10 de marzo de 2005 y 14/2005 de 3 de octubre de 2005, que dieron lugar a tres tesis jurisprudenciales sumamente relevantes: 9, 10 y 11 de $2006^{31}$ ) y Argentina (v.gr., en el caso «Badaro, Adolfo Valentín c/ ANSeS s/ reajustes varios» $\mathrm{I}^{32}$, de 8 de agosto de 2006 , y $\mathrm{II}^{33}$, de 26 de noviembre de 2007, por enumerar algún criterio reciente), en tierras americanas.

30 Sobre el último aserto vertido en el texto (control mediato del poder legislativo), se ha expresado que "[e]l hecho de que se trate de impugnaciones cuyo objeto es de manera inmediata la acción u omisión de los poderes ejecutivo y judicial no excluye la posibilidad de un control mediato del poder legislativo, toda vez que la Sala o la Sección del Tribunal Constitucional que conoce del recurso de amparo puede concluir que la lesión de los derechos fundamentales ocasionada por la acción o la omisión administrativas o judiciales trae en realidad causa de la ley aplicada al caso,...» -bastardilla agregada- (»Los problemas de la omisión legislativa en la jurisprudencia constitucional», Ponencia del Tribunal Constitucional de España, "XIV Conferencia de Tribunales Constitucionales Europeos», Vilna, Lituania, mayo de 2008; Fuente: www.lrkt.lt/conference/Pranesimai/ES-Lituania\%202008.doc).

31 Tituladas: «Principio de división funcional de poderes. Sus características»; «Órganos legislativos. Tipos de facultades o competencias derivadas del principio de división funcional de poderes» y «Omisiones legislativas. sus tipos»; Semanario Judicial de la Federación y su Gaceta, 9a Época, Pleno, T. XXIII, febrero de 2006, pp. 1533, 1528 y 1527, respectivamente.

32 Causa 'B.675.XLI' (Fallos, 329:3089).

El decisorio lleva la firma de los ministros Petracchi, Highton de Nolasco, Fayt, Maqueda, Zaffaroni, Lorenzetti y Argibay.

33 Se trata de un segundo pronunciamiento en la causa identificada en la nota anterior.

Votaron de manera coincidente los ministros Petracchi, Highton de Nolasco, Fayt, Maqueda, Zaffaroni y Lorenzetti. 


\section{E. Reflexión final}

Para concluir este acercamiento, es preciso reenviar a CARRILLO, quien asegura que en Europa (aunque - agregamos por nuestra parte - con reflejos hacia el ámbito latinoamericano), la configuración de la justicia constitucional como mecanismo de defensa de la Constitución, ha supuesto una notable innovación en la función jurídica y política de la Ley Fundamental: desde el punto de vista jurídico, porque no hay duda que la Constitución adquiere progresivamente la condición de norma jurídica exigible ante los poderes públicos y los particulares; y desde la óptica política, porque aquélla ordena el sistema político y los Tribunales Constitucionales se convierten en instrumentos de defensa del ordenamiento constitucional ante el legislador y el resto de los poderes del Estado ${ }^{34}$.

La alusión referencial anterior da pie para reiterar que la discusión en torno a las posibilidades de sustentación jurídico-política del contralor de constitucionalidad sobre las omisiones inconstitucionales representa un capítulo más de la tensión constitucionalismo-democracia, judicatura-Congreso o, en otras palabras, de la delicada vinculación entre jurisdicción y legislación ${ }^{35}$.

Las relaciones tensionales entre el poder judicial o la jurisdicción constitucional y el Congreso o Parlamento deben reconducirse en términos constructivos y, en el contexto específico de la inercia o la mora legislativas anticonstitucionales, la labor jurisdiccional superadora que al respecto se acometa no debería ser impulsada (ni entendida) en un plano confrontativo o de puja de poder, sino desde la vertiente del diálogo y la colaboración comprometidos institucionalmente en la búsqueda de un equilibrio que, sin soslayar la irrenunciable misión del órgano de cierre de la justicia constitucional de conservar inalterada la vigencia normativa suprema de la Constitución, resguarde la estructura del Estado, la división de poderes, la autoridad democrática del legislador y su libertad de configuración política ${ }^{36}$.

34 Carrillo, Marc, «La Jurisdicción Constitucional en Europa: las funciones del Tribunal Constitucional Español y las hipotecas del caso chileno», loc. cit. en nota 2 (Estudios de Teoría del Estado ...), T ${ }^{\circ}$ II, p. 1472.

${ }^{35}$ La frase que cierra este tramo del texto: «la delicada vinculación entre jurisdicción y legislación», es paráfrasis de la apreciación de ZAGREBELSKY, quien alude a «lo delicado de la relación entre jurisdicción y legislación» (ZAGREBELSKY, Gustavo, El derecho dúctil. Ley, derechos, justicia, $3^{a}$ ed., Trotta, trad. de Marina Gascón, Madrid, 1999, p. 152).

36 Ver sobre el punto, BAZÁN, Víctor, "Las omisiones legislativas inconstitucionales y su posible corrección: entre la tensión y el diálogo del Poder Judicial y el Congreso», en GENTILE, Jorge (comp.), El Poder Legislativo. Aportes para el conocimiento del Congreso de la Nación Argentina, Asociación Argentina de Derecho Constitucional y Fundación Konrad Adenauer, Montevideo, 2008, pp. 899/929. 
En esa lógica interactiva es tan importante que la magistratura constitucional actúe imbuida de un activismo prudente, como que el Congreso o Parlamento asuman la crucial importancia de su rol institucional y actúen a la altura de las circunstancias que el Estado Constitucional de Derecho les impone.

\section{Acerca del control de constitucionalidad de los instrumentos internacionales ${ }^{37}$}

\section{A. Aclaración previa}

No se nos escapa que el epígrafe que encabeza estas líneas es de dudosa potabilidad léxico-jurídica. Es que, como los instrumentos internacionales son -por varias razones- fuentes jurídicas diversas de las leyes y demás normas internas, cabe preguntarse si en puridad corresponde hablar de su fiscalización constitucional. Conscientes de ello y aceptando cualquier entendible tacha de impropiedad jurídica en tal sentido, a los efectos prácticos mantenemos en este trabajo la terminología de mención porque en diversos textos constitucionales latinoamericanos se diagrama tal competencia en cabeza del órgano supremo de jurisdicción constitucional.

\section{B. Control constitucional previo y obligatorio}

Dicho lo anterior, advertimos que, como factores de análisis para una visión integral del problema que nos convoca, no cabría soslayar - inter alia - la creciente interdependencia de los Estados, la imposibilidad de aislamiento frente a los fenómenos de globalización e integración económica, la necesaria imagen de seriedad y confiabilidad hacia la comunidad internacional sustentada en la garantía de la seguridad jurídica fronteras adentro y la solidificación de la decisión institucional de dar cumplimiento a los compromisos internacionales que acometa el Estado en cuestión.

En esa realidad contextual no nos parece que la temática en estudio recepte una importancia menor o secundaria; tampoco, que sea indiferente que un determinado ordenamiento jurídico diseñe normativamente o habilite jurisprudencialmente un control de constitucionalidad represivo o posterior de los instrumentos internacionales en vigor.

37 Para ampliar sobre el particular, ver el libro de BAZÁN, Víctor, Jurisdicción constitucional y control de constitucionalidad de los tratados internacionales. Una visión de derecho comparado, Porrúa, México, D.F., 2003. 
Pensamos que una vez que el documento internacional en cuestión se encuentre en vigor e integrado al ordenamiento jurídico interno, resultaría inconveniente habilitar a su respecto un control de constitucionalidad a posteriori, pues si siguiéramos un razonamiento hipotético, ¿qué sucedería si el órgano jurisdiccional constitucional pertinente concluyera que el mismo es total o parcialmente inconstitucional y, al hilo de tal decisión, se optara por no cumplir sus postulados? Percibimos que semejante alternativa podría coadyuvar al debilitamiento del contenido axiológico y jurídico de la exigencia que se impone a todo Estado de honrar sus compromisos internacionales. Ello tampoco supondría - precisamenterespetar los principios generales del derecho internacional y, ya en particular, las pautas pacta sunt servanda (norma fundamental de todo el derecho de los tratados), cumplimiento de buena fe e improcedencia de alegar disposiciones de derecho interno para justificar el incumplimiento de los acuerdos internacionales, y, por el contrario, propiciaría el demérito de la seguridad jurídica y el desencadenamiento de la responsabilidad internacional del país en cuestión.

\section{Breve referencia al derecho comparado}

De un rápido recorrido por un sector de la preceptiva constitucional latinoamericana (Colombia, Ecuador, Bolivia, Chile, Venezuela), tomado sólo para graficar la problemática expuesta, surge que — aunque con matices—, en aquél se diagrama por vía de principio un control de constitucionalidad previo o preventivo de los instrumentos internacionales, que puede ser:

- Obligatorio, v.gr., en Colombia o Ecuador. En este último país, tal modalidad fiscalizatoria fue establecida en la Constitución de $1998^{38}$ y puesta a cargo del Tribunal Constitucional; y actualmente, esto es, según el citado texto constitucional vigente luego del referéndum de 28 de septiembre de 2008, el art. 438, inc. $1^{\circ}$, estatuye que la Corte Constitucional (que sustituye al Tribunal Constitucional) emitirá dictamen previo y vinculante de constitucionalidad respecto de los tratados internacionales, con anterioridad a su ratificación por parte de la Asamblea Nacional;

38 Ello así, cuando se tratara de aquellos instrumentos que requirieran la aprobación del Congreso Nacional, es decir, los enumerados en el entonces artículo 161 constitucional. O sea, que se refirieran a materia territorial o de límites; que establecieran alianzas políticas o militares; que comprometieran al país en acuerdos de integración; que atribuyeran a un organismo internacional o supranacional el ejercicio de competencias derivadas de la Constitución o la ley; que se refirieran a los derechos y deberes fundamentales de las personas y a los derechos colectivos; y que contuvieran el compromiso de expedir, modificar o derogar alguna ley. 
- facultativo o potestativo, por ejemplo, en Bolivia — según la reforma constitucional de 1994- competencia que recaía en el Tribunal Constitucional. Debe advertirse que, de acuerdo con la actual Constitución aprobada por el referéndum de 25 de enero de 2009 (que abroga la Constitución Política del Estado de 1967 y sus reformas), y con una redacción un poco confusa, el art. 203 , inc. $9^{\circ}$, establece como atribución del Tribunal Constitucional Plurinacional (que tal Ley Fundamental prefigura) el control previo de constitucionalidad en la ratificación de tratados internacionales ${ }^{39}$.

- obligatorio y facultativo según las hipótesis de que se trate, lo que se verificaría en el supuesto de Chile a partir de la reforma constitucional de 2005, donde se habría programado un control obligatorio de los tratados referentes a materias que en el derecho interno son objeto de ley orgánica constitucional; y, fuera de esta hipótesis, un contralor facultativo a iniciativa de ciertos órganos o autoridades del Estado, antes de la remisión de la comunicación que informa la aprobación del tratado por el Congreso Nacional y, en caso alguno, después del quinto día del despacho de dicha comunicación.

D. El desafío que en el particular recae sobre la justicia constitucional

Nos pronunciamos, por tanto, a favor del control preventivo o a priori de constitucionalidad de los instrumentos internacionales. Incluso, y para evitar potenciales inconvenientes en el despliegue vivencial de los mismos, pensamos que sería aconsejable pautar que dicha fiscalización fuese obligatoria, en orden a prevenir contradicciones o disturbios jurídicos ad intra e intensificar, así, el celo en la preservación de la supremacía constitucional; coadyuvar al manteni-

39 Es de hacer notar que la Disposición Transitoria Novena determina: «Los tratados internacionales anteriores a la Constitución y que no la contradigan se mantendrán en el ordenamiento jurídico interno, con rango de ley. En el plazo de dos años desde la elección del nuevo Órgano Ejecutivo, éste denunciará y, en su caso, renegociará los tratados internacionales que sean contrarios a la Constitución».

Por su parte, el art. 410 estipula: «La Constitución es la norma suprema del ordenamiento jurídico boliviano y goza de primacía frente a cualquier otra disposición normativa.

«La aplicación de las normas jurídicas se regirán por la siguiente jerarquía:

$1^{\circ}$ La Constitución.

$2^{\circ}$ Las leyes y los tratados internacionales.

$3^{\circ}$ Los decretos supremos.

$4^{\circ}$ Las normas departamentales, regionales y municipales.

$5^{\circ}$ Normas de carácter administrativo». 
miento de la coherencia y lógica del sistema interno de fuentes, y evitar la vinculación jurídica del Estado pertinente en el ámbito internacional sin proceder, previamente, a las adaptaciones normativas correspondientes (por ejemplo, una reforma constitucional) o, en su caso, a desistir de la aprobación del documento internacional o a concretarla con reservas.

Justamente, el reto de la jurisdicción constitucional radica en evitar que la praxis jurisprudencial desnaturalice o erosione el sustrato de las disposiciones específicas de las respectivas regulaciones constitucionales que han estatuido una modalidad preventiva o previa de constitucionalidad de los instrumentos internacionales, habilitando vías heterodoxas para canalizar el control a posteriori.

\section{En torno a la participación de amicus curiae en los procesos constitucionales ${ }^{40}$}

\section{A. Breve descripción de la figura}

Esencialmente, pueden comparecer al proceso en calidad de amici curiae las personas físicas o jurídicas, siempre que acrediten reconocida competencia en la temática en examen; su intervención no los convierte en parte; y su actividad queda ceñida a expresar una opinión fundada en defensa de un interés público o de una cuestión institucional relevante.

Su participación se materializa a través de una actividad de alegación sobre el tema que constituye el objeto de una decisión jurisdiccional, tarea que realizan como terceros, es decir, como personas ajenas a la relación jurídico-procesal pero interesadas en el resultado del proceso ${ }^{41}$.

En específica referencia al ámbito jurídico norteamericano, aunque con utilidad argumental expansiva, se ha indicado que dentro del modelo dialógico de creación de precedentes, el amicus curiae permite la ampliación de participantes en el debate. Así, mientras mayor sea la participación de ideas en la discusión constitucional, mayor será la legitimidad del precedente que se establezca y, al mismo tiempo, se cumplirá con el fundamento democrático de que las normas son autoimpuestas y, de allí, obligatorias y legítimas ${ }^{42}$.

40 Sobre el tema, ver BAZÁN, Víctor, por ejemplo en «Amicus curiae, transparencia del debate judicial y debido proceso", Anuario de Derecho Constitucional Latinoamericano 2004, T $\mathrm{II}$, Fundación Konrad Adenauer, Montevideo, 2004, pp. 251/280.

${ }^{41}$ Cfr. Trionfetti, Víctor, «El enriquecimiento del debate judicial a través de la figura del amicus curiae», La Ley, T' 2003-F, Buenos Aires, p. 71.

42 SOLA, Juan V., "El recurso extraordinario y el debate constitucional», en el 'Número especial: Recurso extraordinario federal', Jurisprudencia Argentina, LexisNexis, 26 de marzo de 2003, Buenos Aires, p. 95. 
El amicus curiae puede coadyuvar a garantizar el debido proceso y brindar nuevos elementos de análisis o enfoques jurídicos idóneos para realzar cualitativamente las decisiones judiciales, al tiempo que la posibilidad de fundar éstas en argumentos públicamente ponderados constituye un factor suplementario de legitimidad $^{43}$ de la actuación de la jurisdicción constitucional.

Asimismo, puede adquirir relevancia en casos complejos o cuestiones que planteen un dilema ético o de otra índole y que la sentencia que las dirima no agote sus efectos en la hipótesis concreta sino que ostente fuerza expansiva hacia otros supuestos o procesos pendientes.

B. Sumario relevamiento de algunos antecedentes en el derecho comparado

El empleo de la figura se hace patente en diversas instancias iusinternacionales, por ejemplo, en la Corte Interamericana de Derechos Humanos (Corte IDH); el Tribunal Europeo de Derechos Humanos; los órganos de supervisión del sistema africano, establecido por la Carta de los Derechos Humanos y de los Pueblos; el Tribunal Penal Internacional para la ex Yugoslavia; los Paneles y el Cuerpo de Apelación de la Organización Mundial del Comercio; y hasta en el Centro Internacional de Arreglo de Diferencias Relativas a Inversiones (CIADI).

Ya en el plano del derecho interno estatal, es preciso destacar enunciativamente algunos casos de implementación de la figura por los respectivos órganos máximos de la jurisdicción constitucional. Nos referimos a la Corte Suprema de Justicia de Argentina, el Tribunal Constitucional del Perú y el Supremo Tribunal Federal del Brasil.

En el caso argentino, y sin ley expresa que establezca de modo genérico el instituto, la Corte Suprema dictó la Acordada N ${ }^{\circ} 28^{44}$, de 14 de julio de 2004, en la que autorizó - por mayoría - la intervención de "amigos del Tribunal», cuya presentación, que puede concretarse en todos los procesos judiciales correspondientes a la competencia originaria o apelada del Tribunal en los que se debatan asuntos de trascendencia colectiva o interés general, habrá de ser realizada con la única finalidad de expresar una opinión o una sugerencia fundadas

43 Véase, mutatis mutandi, ABREgú, Martín y COURTIS, Christian, «Perspectivas y posibilidades del amicus curiae en el derecho argentino», en el volumen colectivo compilado por dichos autores: La aplicación de los tratados sobre derechos humanos por los tribunales locales, CELS, Editores del Puerto, Buenos Aires, 1997, p. 388.

44 Vid. sobre el particular, BAZÁN, Víctor, «El amicus curiae en el derecho comparado y su instrumentación reglamentaria por la Corte Suprema de Justicia argentina", Anuario Iberoamericano de Justicia Constitucional, No 10, 2006, CEPC, Madrid, 2006, pp. 15/50. 
sobre el objeto del litigio en defensa de un interés público o de una cuestión institucional relevante.

Ya en lo que atañe a Perú, el art. 13.A del Reglamento Normativo del Tribunal Constitucional (aprobado mediante Resolución Administrativa $N^{\circ} 095-$ 2004-P-TC) establece: «El Pleno o las Salas pueden solicitar información de los amicus curiae (amici curiarum), si fuera el caso, a fin de esclarecer aspectos especializados que puedan surgir del estudio de los actuados». Por su parte, el art. 34 de dicho Reglamento, determina: «Luego de instalada la audiencia, el Presidente dispone que el Relator dé cuenta, en forma sucesiva, de las causas programadas, precisando el número de expediente, las partes que intervienen y la naturaleza de la pretensión. El Presidente concede el uso de la palabra, hasta por cinco minutos al demandante y por igual tiempo al demandado, quienes se ubicarán a la izquierda y la derecha, respectivamente, frente a los Magistrados. A continuación, el Presidente concede el uso de la palabra a los abogados del demandante y del demandado, por el mismo tiempo, los cuales se ubicarán en igual forma que sus defendidos. Está permitida la réplica y duplica a los abogados por el tiempo que determine el Presidente. Por último, cuando corresponda, se recibirá la participación del amicus curiae». Para finalizar esta breve referencia, y ciñéndonos ahora a la jurisprudencia del Tribunal, pueden relevarse ejemplificativamente los siguientes casos de operativización práctica de la figura: Exptes. 020-2005-PI/TC y 021-2005-PI/TC (acumulados, Caso Hoja de Coca), sentencia de 27 de septiembre de 2005 (Pleno Jurisdiccional); y Expte. 3.0812007-PA/TC, Lima, «R.J.S.A. vda. de R.», recurso de agravio constitucional en proceso de amparo en torno a la problemática de la salud mental, resuelto el 9 de noviembre de 2007 (Sala Segunda).

También el Supremo Tribunal Federal (STF) de Brasil, aun antes de la enmienda reglamentaria $N^{\circ} 15 / 04$ que modificó el $\$ 3^{\circ}$ del art. 131 del Reglamento Interno del STF, para disciplinar la intervención de terceros en procesos de control concentrado de constitucionalidad, ya había decidido algunos procesos de ADIn (Ação Direta de Inconstitucionalidade) viabilizando la participación de terceros; por ejemplo, como señala DA CUNHA FERRAZ, sobre el particular puede verse el relato y el voto del Ministro Celso de Mello en la ADIn 2321-MC/DF, generando una construcción jurisprudencial sobre la figura del amicus curiae que entrañó un verdadero leading case $4^{45}$. Más aún, se ha sostenido que de la interpretación del $\$ 2^{\circ}$ del art. 7 de la Ley $\mathrm{N}^{\circ} 9.868 / 99$, surge que además de los órganos y entidades for-

45 Da Cunha Ferraz, Anna Candida, "O amicus curiae e a democratização e a legitimação da jurisdição constitucional concentrada», Revista Mestrado em Direito. Direitos Humanos Fundamentais, Año 8, No 1, 2008, Unifieo, São Paulo, pp. 65 y ss. 
malmente legitimados para articular la ADIn, también lo están cualesquiera otros entes dotados de significativa representatividad, llegándose a aseverar que el STF permitió la participación de amici curiae ya antes del dictado de tal ley, por ejemplo en la ADIn 748-4/RS (de 1994), receptando los memoriales de amicus curiae al visualizar a éste como colaborador informal del Tribunal en las acciones directas de inconstitucionalidad, sin integrar la relación procesal ${ }^{46}$.

\section{Observaciones adicionales}

Retomando el hilo argumental que desarrollábamos antes de relevar algunos antecedentes que exhibe el derecho comparado, es dable destacar que si la mayoría de los Estados latinoamericanos ha aceptado la jurisdicción contenciosa de la Corte IDH, si además ante ésta existe la posibilidad de comparecer en calidad de amicus curiae y si llegar con un caso ante la misma supone el agotamiento previo de los recursos internos del Estado demandado, requisito éste concedido en interés del propio Estado, resulta entonces absurdo - como enfatizan ABREGÚ y COURTIS ${ }^{47}$ - prohibir a instituciones o grupos interesados presentarse en carácter de amicus ante los tribunales locales (oportunidad frente a la que el Estado tiene posibilidades de remediar la alegada violación) y conceder esa posibilidad después, cuando el Estado ya ha sido demandado ante la Corte por la imputación de los mismos hechos. Por lo demás, siendo la instancia interamericana coadyuvante o complementaria de la que prodiga el derecho interno, es razonable ofrecer a los grupos o instituciones interesados en articular opiniones fundadas sobre el tema en cuestión la misma posibilidad de participación procesal en sede local que la que tienen en el ámbito internacional, adelantando ante los tribunales domésticos los argumentos que eventualmente serán considerados por la Corte IDH.

Para concluir el abordaje del asunto en cuestión, precisamente ésta ha reiterado en fecha relativamente reciente que los amici curiae son presentaciones de terceros ajenos a la disputa, que aportan a la Corte argumentos u opiniones que pueden servir como elementos de juicio relativos a aspectos de derecho que se ventilan ante la misma $a^{48}$, como lo ha manifestado también en un caso cronológicamente

46 Amaury Maia Nunes, Jorge, "A participação do amicus curiae no procedimento da Argüição de Descumprimento de Preceito Fundamental (ADPF)», Direito Público, Año V, No 20, marzo/abril de 2008, Instituto Brasiliense de Direito Público, Brasília, pp. 54/55.

47 ABregú, Martín y CourTis, Christian, op. cit., pp. 392/393.

48 Corte IDH, "Caso Castañeda Gutman vs. Estados Unidos Mexicanos», Sentencia sobre Excepciones Preliminares, Fondo, Reparaciones y Costas, 6 de agosto de 2008, Serie C, No 184, párr. 14. 
cercano $^{49}$, pueden ser presentados en cualquier momento antes de la deliberación de la sentencia correspondiente; añadiendo que conforme a su práctica, los amici curiae pueden incluso referirse a cuestiones relacionadas con el cumplimiento de la sentencia ${ }^{50}$. Asimismo, se ha encargado de resaltar que «los asuntos que son de su conocimiento poseen una trascendencia o interés general que justifica la mayor deliberación posible de argumentos públicamente ponderados, razón por la cual los amici curiae tienen un importante valor para el fortalecimiento del sistema interamericano de protección de los derechos humanos, a través de reflexiones aportadas por miembros de la sociedad, que contribuyen al debate y amplian los elementos de juicio con que cuenta la Corte ${ }^{51}$ —énfasis añadido—.

\section{Sobre la efectivización de los derechos económicos, sociales y culturales}

A. Anotaciones preliminares

Entre los derechos civiles y políticos y los DESC existe unidad conceptual, equivalencia de entidad jurídica e interrelación y complementación; y de ninguna manera media separación antinómica.

En tal sentido, la utilización léxica de la expresión «generaciones de derechos humanos», u otras equivalentes, no puede ni debe afectar aquella unidad conceptual de los derechos, puesto que ellos imbrican en la dignidad humana, obviamente, también unitaria. De ello se sigue —en palabras de GARCía RAMÍREZ- que, planteado el carácter integral de los derechos, corresponde afrontar igualmente el carácter integral de su protección ${ }^{52}$.

$\mathrm{Al}$ ser unitaria la dignidad humana, la bifurcación de los derechos humanos en «categorías» pretendidamente diversas y estancas, sólo conduce a la creación de falsas dicotomías que poco aportan en favor de la indivisibilidad, la universalidad y la interdependencia de los derechos humanos, sean éstos civiles y políticos o económicos, sociales y culturales.

No es un secreto que los enfoques atomizados o fragmentados, como el que subyace en la tesis de las "generaciones de derechos humanos", han dificultado la

49 Corte IDH, «Caso Kimel vs. Argentina», Sentencia de Fondo, Reparaciones y Costas, 2 de mayo de 2008, Serie C, No 177, párr. 16.

50 Ídem nota 48.

51 Ídem.

52 García Ramírez, Sergio, «Protección jurisdiccional internacional de los derechos económicos, sociales y culturales», Cuestiones constitucionales, $\mathrm{N}^{\circ}$ 9, julio-diciembre de 2003, IIJ, UNAM, México, D.F., p. 131. 
evolución del derecho internacional de los derechos humanos ${ }^{53}$ en la dimensión fáctica.

$\mathrm{Al}$ menos, podríamos convenir en que tal estereotipada fórmula no puede ser aceptada acríticamente, sino que, como alternativa de "mínima», debe ser repensada, verificando si, en definitiva, es léxica, histórica y jurídicamente correcta o simplemente una creación discursiva arbitraria ${ }^{54}$.

Prestigiosa visión autoral formula serias objeciones a la tesis de la escisión generacional de los derechos. En efecto, y sólo por citar algunos ejemplos, CANÇADO TRINDADE alude a la "fantasía de las generaciones de derechos" ${ }^{55}$; RABOSSI destaca que la consecuencia más dañina que tal doctrina genera es que implica y/o brinda un argumento a quienes sostienen que entre los derechos humanos civiles y políticos y los derechos humanos económicos, sociales y culturales existe una diferencia categorial de fondo o una distinción esencial ${ }^{56}$; por su parte, y entre otros cuestionamientos, PINTO enfatiza que la elección de la variable en que se sustenta dicha tesis es "caprichosa» ${ }^{57}$ y que la consistente doctrina de la universalidad, la interdependencia y la indivisibilidad de los derechos humanos se ve muy «contrariada» con la fórmula de las generaciones de derechos ${ }^{58}$.

Se impone la necesidad de fortalecer los mecanismos internos de exigibilidad y justiciabilidad de los DESC, como paso previo a la articulación de los resortes transnacionales, dado que — como anticipábamos- la jurisdicción internacional es complementaria o coadyuvante de la nacional ${ }^{59}$.

\section{B. Recorrido jurisprudencial}

Descendiendo de tal marco teórico para enfocar la aplicación práctica del desiderátum tuitivo de tales derechos, puede verse en el caso específico de Bolivia que

53 Cfr. Cançado Trindade, Antônio A., en el prólogo a la obra de Pinto, Mónica, Temas de derechos humanos, Editores del Puerto, Buenos Aires, 1997, p. II.

${ }^{54}$ RABOSSI, Eduardo, "Las generaciones de derechos humanos: la teoría y el clichén, Lecciones y Ensayos, Nos. 69/70/71, 1997-98, Facultad de Derecho y Ciencias Sociales, Universidad de Buenos Aires, Abeledo-Perrot, Buenos Aires, pp. 41 y ss., pássim.

55 Así la denomina CANÇADO TRINDADE, Antônio A., "Derechos de solidaridad», en CERDAS CruZ, Rodolfo y NieTo LoAYZA, Rafael (comps.), Estudios Básicos de Derechos Humanos, T ${ }^{\circ}$ I, Instituto Interamericano de Derechos Humanos, San José de Costa Rica, 1994, p. 64.

56 Rabossi, Eduardo, op. cit., pp. 49/50.

57 PinTo, Mónica, op. cit., p. 56.

58 Ibid., p. 57.

59 Ver para ampliar, entre otros trabajos de BAZÁN, Víctor, «Vías de maximización protectiva de los derechos económicos, sociales y culturales», La Ley, T² 2007-D, Buenos Aires, pp. $1135 / 1149$. 
su Tribunal Constitucional ha seguido una laudable vertiente jurisprudencial protectoria. Pueden citarse, en esa dirección, las Sentencias Constitucionales 411/2000R, de 28 de abril de 2000, que obliga al Estado a proporcionar tratamiento médico a una enferma crónica y a la realización de hemodiálisis a enfermos renales; 433/2000-R, 530/2000-R y 1.052/2001-R, todas sobre tratamientos médicos de personas con enfermedades crónicas; 0026/2003-R, de 8 de enero de 2003, sobre provisión de tratamiento y medicamentos antirretrovirales a personas con VIHSIDA; o la 1.871/2003-R, de 15 de diciembre de 2003, acerca de la protección que debe dispensarse a la mujer embarazada (respecto de quien, a pesar de su estado de gravidez, se había ordenado su detención preventiva, desconociendo la especial protección que la Constitución Política reconoce a favor de la maternidad).

Otro tanto ha sucedido en Argentina, donde con una tónica activista la Corte Suprema de Justicia ha proporcionado cobertura tuitiva al derecho a la salud, reconocido como derecho fundamental, por ejemplo, in re «M.2648.XLI, 'María, Flavia Judith c/ Instituto de Obra Social de la Provincia de Entre Ríos y Estado Provincial' $"{ }^{60}$, de 30 de octubre de 2007; a los derechos laborales, v.gr., declarando la inconstitucionalidad de algunas normas de la Ley de Riesgos del Trabajo (»Castillo, Ángel Santos c/ Cerámica Alberdi S.A.» ${ }^{61}$, de 7 de septiembre de 2004, y "Aquino, Isacio c/ Cargo Servicios Industriales S.A. s/ art. 39 Ley $24.557{ }^{62}$, de 21 de septiembre de 2004) o del tope tarifario implementado en

${ }^{60}$ Fallo por el que revocó la sentencia que había rechazado la acción de amparo tendiente a obtener la cobertura integral de los gastos para la atención de una persona con discapacidad de naturaleza motora, mental, visceral y sensorial grave, en virtud de existir un reclamo similar en sede administrativa, pues -entre otros argumentos- la Corte consideró en el voto mayoritario que siempre que se amerite el daño grave e irreparable que se causaría remitiendo el examen de la cuestión a los procedimientos ordinarios, los jueces deben habilitar las vías del amparo, ya que la existencia de otras vías procesales que puedan obstar a su procedencia no puede formularse en abstracto sino que depende de la situación concreta a examinar. En síntesis, por mayoría, y al tiempo de dejar sin efecto el pronunciamiento recurrido, ordenó se remitieran los autos al tribunal de origen para que, por quien correspondiera, se dictara un nuevo decisorio con arreglo al criterio que sentaba el Alto Tribunal.

Los posicionamientos en el Tribunal fueron los siguientes: por la mayoría, los doctores Lorenzetti, Fayt y Maqueda; en sendos votos concurrentes, los ministros Highton de Nolasco y Zaffaroni; y, por último, en disidencia conjunta, los doctores Petracchi y Argibay.

${ }^{61}$ Fallos, 327:3610.

Votaron coincidentemente los doctores Petracchi, Belluscio, Fayt, Boggiano, Maqueda, Zaffaroni y Highton de Nolasco.

62 Fallos, 327:3753.

La posición triunfante fue sustentada por los doctores Petracchi y Zaffaroni. A su turno, por su voto se pronunciaron los ministros Belluscio y Maqueda, en concurrencia conjunta, y Highton de Nolasco y Boggiano, en mociones individuales. 
la Ley de Contrato de Trabajo para la cuantificación de la indemnización por despido incausado (»Vizzoti, Carlos Alberto cl AMSA S.A. s/ despido»" ${ }^{63}$, de 14 septiembre de 2004); defensa de la vivienda única y familiar (»Rinaldi, Francisco Augusto y otro c/ Guzmán Toledo, Ronal Constante y otra s/ ejecución hipotecaria» ${ }^{64}$, de 15 de marzo de 2007); movilidad de haberes previsionales ("Sánchez, María del Carmen c/ ANSeS s/ reajustes varios» ${ }^{65}$, de 17 de mayo de 2005; y en las citadas causas "Badaro» I y $\mathrm{II}^{66}$.

También es interesante relevar un temperamento consonante del Tribunal Constitucional del Perú, por ejemplo, en Expte. No 2.945-2003-AA/TC, in re "A.A.M.G.» (Sala Primera), en el que ordenó que se considerara a la recurrente en el grupo de pacientes que recibirían tratamiento integral contra el VIH/SIDA por parte del Ministerio de Salud, lo que incluiría la provisión de medicamentos y análisis correspondientes, según lo dispuesto por los médicos del hospital tratante y bajo su responsabilidad, al tiempo de exhortar a los poderes públicos a que se cumpla lo dispuesto en el art. 8 de la Ley $\mathrm{N}^{\circ} 26.626$, debiendo considerarse como inversión prioritaria el presupuesto para la ejecución del Plan de Lucha contra el SIDA. En dirección convergente, pueden contabilizarse las sentencias recaídas en Expte. 6.572-2006, sobre pensión por viudez en caso de unión de hecho, y 4.646-2007, relativa al derecho a la educación.

Para cerrar este sumario señalamiento jurisprudencial, son igualmente dignos de destacar ciertos aspectos de la labor de la Corte Constitucional de Colombia, Corporación que en el marco de la acción de tutela ha realizado una interesante labor hermenéutica sobre el carácter o incidencia sociales de aquella acción, además de haber empleado con frecuencia la denominada argumentación "por conexidad», para "comunicar» a otros derechos (como el de la salud) el carácter de «fundamentalidad» que poseen intrínsecamente algunos (como el derecho a la vida); por ejemplo, mutatis mutandi, las Sentencias T-571 de 1992, justamente

\section{${ }^{63}$ Fallos, 327:3677.}

Se pronunciaron de modo consonante todos los ministros firmantes, doctores Petracchi, Belluscio, Fayt, Boggiano, Maqueda, Zaffaroni y Highton de Nolasco.

${ }^{64}$ Fallos, 330:855.

Los alineamientos fueron los siguientes: el voto que encabeza la sentencia correspondió a los ministros Highton de Nolasco y Maqueda; concurrentemente, en forma conjunta y coincidiendo con éstos en sus primeros once considerandos, se expidieron los doctores Lorenzetti y Zaffaroni; y, finalmente, la doctora Argibay se expidió por su voto.

${ }^{65}$ Fallos, 328:1602.

La mayoría quedó constituida con los doctores Petracchi, Belluscio, Fayt, Highton de Nolasco y Lorenzetti. A su turno, concurrentemente votaron los ministros Zaffaroni y Argibay, de modo conjunto, y Maqueda, individualmente. Por último, en disidencia se expidió el doctor Boggiano. ${ }^{66}$ Ver supra, notas 32 y 33 a pie de página. 
sobre el derecho a la salud, o T-079 de 2008, en torno al derecho a una vivienda adecuada. Tal vez en el «debe» queda la sentencia de 12 de marzo de 2008, en la que el Tribunal por mayoría entendió que existía «cosa juzgada» respecto de la pretensión de análisis de constitucionalidad de los arts. 25, 26, 28 y 51 de la Ley $\mathrm{N}^{\circ} 789 / 2002$ de reforma laboral, aferrándose a un decisorio anterior (de 2004) $\mathrm{y}$, por tanto, se abstuvo de realizar el examen constitucional requerido, pese a que dicha reforma laboral había disminuido la protección de los derechos de los trabajadores y no produjo los resultados esperados en materia de generación de nuevos empleos. Fuera y más allá de los pronunciamientos enunciados, no puede omitirse siquiera una mínima alusión a un decisorio trascendente: la Sentencia T-025 de 2004 sobre desplazamiento forzado interno (correspondiente a la Sala $3^{\mathrm{a}}$ de Revisión de la Corte Constitucional), que determinó al respecto un «estado de cosas inconstitucional» ante las condiciones de vulnerabilidad extrema en las cuales se encontraba la población desplazada y la omisión reiterada de brindar protección oportuna y efectiva por parte de las distintas autoridades, violándose los derechos a la vida digna, integridad personal, igualdad, petición, trabajo, salud, seguridad social, educación, minimo vital y protección especial a personas de la tercera edad, mujeres cabeza de familia y niños.

\section{Derechos en serio}

En síntesis, lo ideal sería que el Estado previera y evitara posibles incumplimientos en el campo de los DESC, pero si ellos igualmente se configuraran, los remedios nacionales darían a aquél ocasión de repararlos localmente antes de que se activen en su contra las instancias transnacionales. En un marco genérico de discusión, creemos que no es posible soslayar la existencia de una directriz axiológicamente relevante que en todo momento debe ser tenida en consideración tanto por las autoridades pertinentes en el ámbito interno cuanto por los órganos competentes en la dimensión internacional en el respectivo desarrollo de sus funciones: los derechos humanos son la expresión directa de la dignidad de la persona humana ${ }^{67}$, sean ellos civiles y políticos o económicos, sociales y culturales.

${ }^{67}$ Instituto de Derecho Internacional, Resolución sobre «La protección de los derechos humanos y el principio de no intervención en los asuntos internos de los Estados», adoptada en la sesión de Santiago de Compostela, el 13 de setiembre de 1989; aludida por CARRILlo SALCEDO, Juan Antonio, en el Prólogo a la obra de CANÇADO TRINDADE, Antônio A., El acceso directo del individuo a los Tribunales Internacionales de derechos humanos, Universidad de Deusto, Bilbao, 2001, pp. 11/12. 
Aprehender tal premisa configuraría un buen punto de partida para superar preconceptos, abandonar concepciones que ven en los DESC ciertos «defectos congénitos» que obstan a catalogarlos como verdaderos «derechos» o a adjudicarles algún "valor jurídico» ${ }^{68}$, y dejar de lado percepciones que, al mantener que aquéllos no generan obligaciones estatales correlativas, preconizan la «irresponsabilidad» del Estado en caso de incumplimiento de normas nacionales o internacionales que los reconozcan.

Como contrapartida, creemos que tales esfuerzos deberán canalizarse constructivamente y, al superar relativismos y escepticismos, convertirse en aportes para crear, modular y repensar técnicas de realización, vías de maximización o mecanismos de garantía de los derechos económicos, sociales y culturales que coadyuven definitivamente a ponerlos en acción ${ }^{69}$.

En esa línea, y más allá de los casos puntuales esquematizados, se impone una profundización de la labor de la jurisdicción constitucional latinoamericana en el ámbito temático relevado y un dinamismo prudente para generar estándares jurisprudenciales sustentables que, sin resultar temerarios ni atentar contra el equilibrio financiero del Estado, coadyuven a la realización de semejantes derechos que, sin duda, se presentan directamente consustanciados con la dignidad de la persona.

\section{La interacción de la jurisdicción constitucional interna con los tribunales internacionales para fortalecer la preservación de los derechos fundamentales}

\section{A. Planteo del tema}

Nos interesa ahora resaltar el relevante papel que los magistrados constitucionales están llamados a jugar en el Estado Constitucional de Derecho, fundamentalmente en contextos cuyos paisajes jurídicos han sido impactados fuertemente por el derecho internacional de los derechos humanos, como - por citar sólo un ejemplo- el argentino al influjo de la reforma constitucional operada en $1994^{70}$.

${ }^{68}$ Ver al respecto, la respuesta que a tales objeciones brinda COURTIS, Christian, «Los derechos sociales como derechos", en AA.VV., Los derechos fundamentales, Seminario en Latinoamérica de Teoría Constitucional y Política 2001, Editores del Puerto, Buenos Aires, 2003, pp. 198 y ss.

${ }^{69}$ Sobre el tema, ver BAZÁn, Víctor, por ejemplo en «Los derechos económicos, sociales y culturales en acción: sus perspectivas protectorias en los ámbitos interno e interamericano", Anuario de Derecho Constitucional Latinoamericano 2005, T II, Fundación Konrad Adenauer, Montevideo, 2005, pp. 547/583.

${ }^{70}$ Ver supra en nota 23 a pie de página. 
La delicada misión que la magistratura constitucional ostenta como último reducto para la defensa y efectivización de los derechos fundamentales en el ámbito vernáculo deberá ser afrontada y desplegada conociendo y asumiendo la importancia axiológica de las fuentes jurídicas internacionales (instrumentos internacionales sobre derechos humanos, costumbres internacionales consolidadas y principios generales del derecho de las naciones civilizadas), las que habrán de emplearse como guía en la trascendente tarea de interpretación y aplicación de los preceptos de la Ley Fundamental por parte de la jurisdicción constitucional y, también y de acuerdo con la valencia que en la propia Constitución se les asigne vis-à-vis el derecho doméstico, como parámetros de control de la normativa infraconstitucional, es decir, fiscalizando la adecuación a ellas de las leyes y normas infralegales.

Y todo porque no hacerlo así podría significar — más allá de una objetable despreocupación por la dignidad humana- que el Estado en cuestión incurra en responsabilidad internacional, pues por ejemplo respecto del orden jurídico interamericano, ser parte de la CADH genera tanto un deber de respeto a los derechos humanos como un deber de garantía de éstos.

Conviene entonces pulsar el botón de alerta en torno a diversas cuestiones de interés, que deberán ser repensadas por la jurisdicción constitucional. Es que en la hora actual los puntos de contacto entre el derecho internacional de los derechos humanos y el derecho interno se multiplican, incrementándose la necesidad de lograr una pacífica articulación de tales fuentes mediante su retroalimentación y complementariedad a favor de la solidificación del sistema general de derechos, lo que es tan sencillo de predicar dialécticamente como difícil de plasmar en la realidad.

B. Retroalimentación de los controles de constitucionalidad y convencionalidad

Por su parte, no puede omitirse señalar que la Corte IDH ha emitido en fecha reciente una sentencia en la que deja un claro mensaje a los jueces internos. Se trata del caso "Almonacid Arellano», de 26 de septiembre de 2006, donde se ha pronunciado en los siguientes términos: «La Corte es consciente que los jueces y tribunales internos están sujetos al imperio de la ley y, por ello, están obligados a aplicar las disposiciones vigentes en el ordenamiento jurídico. Pero cuando un Estado ha ratificado un tratado internacional como la Convención Americana, sus jueces, como parte del aparato del Estado, también están sometidos a ella, lo que les obliga a velar porque los efectos de las disposiciones de la Convención no se vean mermados por la aplicación de leyes contrarias a su ob- 
jeto y fin, y que desde un inicio carecen de efectos jurídicos. En otras palabras, el Poder Judicial debe ejercer una especie de 'control de convencionalidad' entre las normas jurídicas internas que aplican en los casos concretos y la Convención Americana sobre Derechos Humanos. En esta tarea, el Poder Judicial debe tener en cuenta no solamente el tratado, sino también la interpretación que del mismo ha hecho la Corte Interamericana, intérprete uiltima de la Convención Americana»(remarcado añadido) $)^{71}$.

Dicho de otro modo, la Corte IDH impone a los poderes judiciarios de los Estados (ordinarios y/o constitucionales, según corresponda) la obligación de concretar el control de convencionalidad de las normas jurídicas internas que aplican en los casos concretos vis-à-vis la $\mathrm{CADH}$, tomando en consideración al efecto no sólo la literalidad de dicho pacto sino la lectura que del mismo ha realizado el tribunal interamericano, que, como se sabe, es el intérprete último de aquél. Realza, así, la operatividad de la pauta de interpretación conforme a la $C A D H$ como estándar hermenéutico a respetar y resguardar por parte de los órganos jurisdiccionales vernáculos, dinámica en la que subyace la idea de retroalimentación entre el control de constitucionalidad y el control de convencionalidad.

\section{Algunas zonas de confluencia potencialmente tensionales}

Para finalizar este señalamiento (y dar paso a las apreciaciones de cierre del trabajo), y en lista no taxativa de aquellas importantes zonas de confluencia entre ambas dimensiones (interna e internacional) que representan otros tantos desafíos para las respectivas jurisdicciones constitucionales, pueden incluirse los siguientes aspectos:

- el temperamento adoptado por la Norma Fundamental respectiva al asignar un determinado tenor jerárquico a los instrumentos internacionales sobre derechos humanos frente al derecho interno o, en su defecto, al silencio que puede guardar sobre el particular; hipótesis esta última donde aflora en plenitud la relevancia de la tarea hermenéutica a cargo de la justicia constitucional para descifrar la valencia posicional de tales documentos internacionales en el plano vernáculo y paralelamente mantener una interacción armónica de las fuentes local y transnacional;

71 Corte IDH, «Caso Almonacid Arellano y otros vs. Chile», Sentencia sobre Excepciones Preliminares, Fondo, Reparaciones y Costas, 26 de septiembre de 2006, Serie C, № 154, párr. 124. 
- la cotización que los máximos tribunales nacionales brindan a los pronunciamientos de los órganos protectorios del sistema interamericano: Comisión y Corte Interamericanas; y

- finalmente, la ardua problemática de la ejecución de las sentencias del tribunal interamericano en sede nacional, tópico que entraña uno de los retos más trascendentes a los que se enfrenta todo propósito real de fortalecimiento del modelo tuitivo regional de los derechos humanos.

\section{EPÍlOGO}

La lucha de la jurisdicción constitucional por legitimarse social y democráticamente, pugnar por su independencia funcional y económica, superar la insuficiencia presupuestaria, entronizarse como eficaz instrumento de defensa de la Constitución y garante final de los derechos humanos en los respectivos ámbitos internos; son sin duda problemáticas comunes que se enseñorean de los respectivos espacios donde operan los órganos de la magistratura constitucional pertinente en distintas latitudes del arco latinoamericano ${ }^{72}$.

La utilización equilibrada y razonada de sentencias «atípicas» o «intermedias», que pueden resultar provechosas en la dinámica del modelo constitucional; la incursión en espacios inhóspitos del control de constitucionalidad como el de la fiscalización sobre las pretericiones inconstitucionales; el mantenimiento del esquema de contralor de constitucionalidad previo y obligatorio de los instrumentos internacionales (si así viniera estatuido en las respectivas Constituciones); la articulación de nuevas fórmulas de participación de la ciudadanía en los procesos constitucionales, por ejemplo, a través de la figura del amicus curiae; la tonificación de los mecanismos internos de exigibilidad y justiciabilidad de los derechos económicos, sociales y culturales; la búsqueda de una madura y eficaz interacción de la jurisdicción constitucional interna con los tribunales internacionales para fortalecer la salvaguardia de los derechos fundamentales; no son sino algunos de los desafíos temáticos que figuran en una agenda imaginaria que el Siglo XXI impone a la justicia constitucional en Latinoamérica.

Por su parte, la observación de las experiencias normativas (constitucionales o subconstitucionales) y jurisprudenciales en Europa y Latinoamérica (éstas por medio de las citadas modalidades sentenciales «atípicas» $\mathrm{o}$ «intermedias»),

72 Un acercamiento al tema puede compulsarse en BAZÁN, Víctor, «Algunos problemas y desafíos actuales de la jurisdicción constitucional en Iberoamérica», Anuario de Derecho Constitucional Latinoamericano 2007, T I, Fundación Konrad Adenauer, Montevideo, 2007, pp. 37/61. 
pone al descubierto el creciente interés por institucionalizar o aplicar pretorianamente diversos mecanismos para superar o corregir las omisiones inconstitucionales. Cuando menos, crece la convicción de que la doctrina de la inconstitucionalidad por omisión tiene algo que aportar en favor de la fluidez del tránsito de la supremacía constitucional, la vigencia real de los derechos y la consolidación del Estado Constitucional de Derecho.

Las fricciones entre el Congreso y el Tribunal Constitucional o el poder judicial (de acuerdo con las respectivas adscripciones a los diversos sistemas de contralor de constitucionalidad) deben recanalizarse en términos de diálogo y convivencia institucional madura y no ser concebidas desde un prisma confrontativo o de lucha de poder. Ello, en el marco de una deseable dinámica armónica que sin mengua de la insoslayable tarea del órgano de cierre de la jurisdicción constitucional en punto a preservar la vigencia normativa suprema de la Constitución, al mismo tiempo se muestre respetuoso de la división de poderes y la autoridad democrática del legislador.

Tampoco puede obviarse que los retos y las exigencias relevadas en este trabajo obligan a superar los esquemas y moldes del Tribunal Constitucional como «legislador negativo», exigiéndole — como mutatis mutandi refiere TAJADURA TEJADA - llegar hasta las últimas fronteras de la Constitución normativa para consolidarse como verdadero Tribunal de los «ciudadanos»" ${ }^{73}$, es decir —añadimos por nuestra parte-, como un Tribunal social.

Y, para ello, es imprescindible una jurisdicción constitucional fuerte, activa, responsable e independiente; pero al mismo tiempo, prudente, equilibrada y consciente de sus límites.

Acierta TORRES Del Moral cuando afirma que «no hay más Constitución que la Constitución democrática, o lo que es igual, la Constitución que instaura y preside un régimen democrático. Y ello por la misma razón de que no hay más Estado de Derecho que el democrático» ${ }^{74}$.

Asociado a ello, se observa así que las bases jurídicas, políticas y axiológicas mínimas de sustentación de un cabal Estado Constitucional y Democrático de Derecho, son: una Constitución suprema y con fuerza normativa, al igual que los instrumentos internacionales básicos en materia de derechos humanos; un sis-

73 Tajadura TejaDA, Javier, «Retos y desafíos de la justicia constitucional en los umbrales del siglo XXI», AA.VV., Visión iberoamericana del tema constitucional, Fundación Manuel García-Pelayo, Caracas, 2003, pp. 438/439.

74 Torres Del Moral, Antonio, «El instituto de la rigidez como garantía de la Constitución», en BAZÁN, Víctor (coord.), Defensa de la Constitución. Garantismo y controles. Libro en reconocimiento al Doctor Germán J. Bidart Campos, Ediar, Buenos Aires, 2003, p. 421. 
tema democrático no declamado sino real; el goce y el ejercicio efectivos de los derechos humanos, porque - como afirma FERRAJOLI- en un Estado de Derecho los derechos exigen ser tutelados, y el progreso de la democracia se mide por la expansión y la justiciabilidad de ellos ${ }^{75}$; y, entre otros elementos, una justicia constitucional que asegure la normatividad y la primacía constitucionales y el respeto y la realización de aquellos derechos sin superfluas distinciones categoriales.

Title

THE CONSTITUTIONAL JUSTICE IN LATIN AMERICA: SOME THEMATIC CHALLENGES FOR CONFRONTING

\section{Summary \\ I. THE WORK PLAN. II. EVALUATION CONTEXT. III. SOME THEMATIC LINES TO TREAT OR DEEPEN. IV. EPILOGUE.}

\section{Resumen}

En el presente trabajo el autor apunta a destacar algunos retos temáticos que sobre la justicia constitucional latinoamericana se posan, y que desafían las posibilidades de robustecimiento de sus roles de defensora de la Constitución, último reducto tutelar de los derechos humanos en el ámbito interno y pieza importante de sostén de la institucionalidad democrática en su función de armonizadora de los poderes del Estado.

Entre otros cuestiones, se aborda la problemática de la utilización de sentencias «atípicas» o «intermedias»; las posibilidades de sustentación del control respecto de las omisiones inconstitucionales; la conveniencia de instrumentar el control de constitucionalidad previo y obligatorio de los instrumentos internacionales o mantenerlo incólume en caso de que ya estuviera así implementado en el texto de la Ley Fundamental; la utilidad de abrir nuevas fórmulas de participación de la ciudadanía en los procesos constitucionales; la necesidad de fortalecer los mecanismos internos de exigibilidad y justiciabilidad de los derechos económicos, sociales y culturales; y la necesaria búsqueda de una pacífica y eficaz interacción de la jurisdicción constitucional interna con los tribunales internacionales para fortalecer la protección de los derechos fundamentales.

${ }^{75}$ Ferrajoli, Luigi, Derecho y razón. Teoría del garantismo penal, 2a ed., Trotta, trad. de Perfecto Andrés Ibáñez y otros, Madrid, 1997, p. 918. 


\title{
Palabras clave
}

Justicia Constitucional. Derecho comparado latinoamericano. Control de constitucionalidad. Sentencias atípicas. Protección de los derechos humanos. Derechos sociales. Relación derecho interno y derecho internacional de los derechos humanos.

\begin{abstract}
In this paper, the author points to highlight some substantial challenges faced by Latin American constitutional justice, which defy the strengthening possibilities of its roles of constitutional champion, final protective human rights domestic redoubt, and important democratic institutionality supportive element when it harmonizes State Branches. Among other things, he addresses issues as the «atypical» or «intermediate» judgments problems; control of unconstitutional omissions maintenance possibilities; convenience of prior and compulsory constitutional control of international instruments implementation or its maintenance where it is already implemented in the Constitution; usefulness of the creation of new formulas to allow community participation in constitutional processes; need to strengthen domestic enforceability and justiciability of economic, social and cultural rights; and the necessary search of a peaceful and effective interaction between domestic constitutional jurisdiction and international courts in order to strengthen fundamental rights protection.
\end{abstract}

\section{Keywords}

Constitutional justice. Latin American comparative law. Constitutional review. Atypical judgments. Human rights protection. Social rights. Domestic law and human rights international law relation 